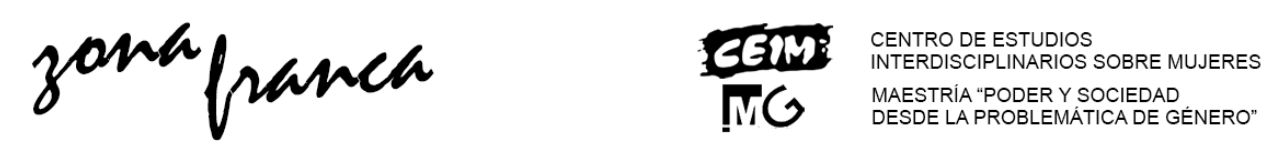

\title{
Rompendo o silêncio do sufoco: A escrita de Esmeralda Ribeiro e Miriam Alves nos Cadernos Negros (Vol.8)
}

\author{
Maria Clara Martins Cavalcanti ${ }^{*}$
}

\section{Resumo}

Em um contexto permeado por diversas opressões de raça e gênero, a escrita das mulheres negras no Brasil têm se configurado historicamente como um espaço potente para o exercício da criatividade e reelaboração de sua própria existência, onde 0 ato de escrever transforma-se em ato político de coragem e a ficção, espécie de abrigo. Em seus contos publicados na Coletânea dos Cadernos Negros Vol.8 (1985), as escritoras negras Anita Realce, Esmeralda Ribeiro e Miriam Alves transitam pelas questões de raça e gênero, denunciando relações de poder, estereótipos misóginos e racistas e, principalmente, reelaborando os discursos sobre as mulheres negras, em uma escrita sobre si e para si. Dessa forma, este trabalho busca entender - apoiado no pensamento de intelectuais como Patrícia Hill Collins, bell hooks, Conceição Evaristo, Gloria Anzaldua e Sueli Carneiro - os entrelaçamentos e complexidades das questões em torno do gênero e da raça que abarcam a literatura de Anita, Esmeralda e Miriam, e as maneiras com que postulam narrativas de contraconduta que se configuram como formas de resistência à mecanismos de poder e dominação como os engendrados pelos racismo e pelo patriarcado.

Palavras-chave: Literatura- Gênero- Raça- Cadernos Negros.

\section{Resumen}

En un contexto impregnado por diversas opresiones de raza y género, la escritura de mujeres negras en Brasil se ha configurado históricamente como un

\footnotetext{
* Mestranda no Programa de Pós-Graduação em História da Universidade Estadual de Campinas, na linha de "Gênero, Cultura Material e Subjetividades". Contacto: mariaclaracavalcanti@id.uff.br
}

Martins Cavalcanti, Maria Clara. "Rompendo o silêncio do sufoco: A escrita de Esmeralda Ribeiro e Miriam Alves nos Cadernos Negros (Vol.8)" en Zona Franca. Revista del Centro de estudios Interdisciplinario sobre las Mujeres, y de la Maestría poder y sociedad desde la problemática de Género, N²7, 2019 pp.61-86. ISSN, 2545-6504 Recibido: 26 de junio 2019; Aceptado: 11 de noviembre 2019

Revista Zona Franca- Centro de estudios interdisciplinario sobre las mujeres (CEIM)- Maestría poder y sociedad desde la problemática de género (MG), Rosario, Argentina. ISSN, 2545-6504 http://zonafranca.unr.edu.ar/index.php/ZonaFrancal Numero 27 (2019). Página 61 
potente espacio para el ejercicio de la creatividad y la reelaboración de su propia existencia, donde el acto de escribir se convierte en un acto político de coraje y la ficción, una especie de refugio. Las escritoras negras Esmeralda Ribeiro y Miriam Alves, en sus historias publicadas en la colección Cadernos Negros Vol.8 (1985), abordan cuestiones de raza y género, denunciando las relaciones de poder, los estereotipos misóginos y racistas y, principalmente, construyen discursos sobre mujeres negras, en una escritura sobre sí y para sí. De esta manera, este trabajo busca comprender, apoyado por los pensamientos de intelectuales como Patricia Hill Collins, Bell Hooks, Conceição Evaristo, Gloria Anzaldua y Sueli Carneiro, las interrelaciones y las complejidades de los temas relacionados con el género y la raza que abarcan la literatura de Esmeralda y Miriam. También espero comprender las formas en que se construyen narrativas de "contraconducta" que se configuran como formas de resistencia a los mecanismos de poder y dominación como los generados por el racismo y el patriarcado.

\section{Palabras claves: Literatura- Género- Raza- Cadernos Negros.}

"Vamos falar da literatura à maneira praticada por nós os negros. No momento nós a praticamos, ela assume um compromisso social personificado. À medida que falamos do nosso lugar duma maneira própria, estamos dizendo coisas que muita gente não quer ouvir, ou tem medo de ouvir. $\mathrm{E}$ nesse exato instante estamos rompendo a máscara da invisibilidade colocada em nós por aqueles

que nos querem negar ou ver à sua maneira, maneira esta que basicamente consiste em nos retratar em um servilismo que não tem outro objetivo senão o de se curvar a vida alheia, que de preferência deve ser a vida de algum branco". (Alves 1985:13)

A epígrafe que inicia este artigo faz parte de um texto introdutório de Miriam Alves para o volume número 8 dos Cadernos Negros', publicado em 1985, e que reúne publicações de 14 escritoras e escritores negros. $O$ trecho aqui escolhido parece por si só trazer à tona uma das características fundamentais da literatura publicada há mais de 30 anos nesta coletânea: ela é um "compromisso social

\footnotetext{
' O Cadernos Negros publica livros anualmente desde 1978. A coletânea surgiu em um contexto de intensa movimentação política dos anos finais da ditadura militar, onde as questões em torno da democracia, da liberdade, dos direitos, etc. estavam em plena discussão e polvorosa. Esse foi um momento de intensas movimentações para o movimento negro no Brasil, marcadas pelas transformações realizadas na efervescência de coletivos literários e organizações do movimento negro da década de 70 que denunciavam e combatiam o mito da democracia racial e a discriminação do povo negro no país. Além disso, buscavam espaço e atuação em lugares até então destinados apenas aos brancos, como certos segmentos das áreas de trabalho, as universidades e o cenário literário. Dessa forma, o Cadernos Negros se tornou uma das maiores plataformas de literatura afro-descendente no Brasil, publicando sem interrupções durante mais de 30 anos coletâneas que revezam poesias e contos de inúmeras escritoras e escritores negros do país. Sua importância tem sido corroborada por importantes pesquisadores da literatura afrobrasileira como Eduardo de Assis Duarte e tema de inúmeras pesquisas na área da Teoria e Estudos Literários.
}

Revista Zona Franca- Centro de estudios interdisciplinario sobre las mujeres (CEIM)- Maestría poder y sociedad desde la problemática de género (MG), Rosario, Argentina. ISSN, 2545-6504 http://zonafranca.unr.edu.ar/index.php/ZonaFrancal Numero 27 (2019). Página 62 
personificado", rompe a "máscara da invisibilidade" (Alves 1985:13) e o "silêncio do sufoco" (Cadernos Negros 1985:5). Desde a sua criação em 1978, a coletânea Cadernos Negros tem reunido autoras e autores negros que, a partir da literatura, trazem à tona o passado de violência e opressão à população negra no Brasil, as permanências das relações de poder herdadas desse passado e suas dores consequentes (Duarte 2011). Além disso, ao mesmo tempo em que se dedicam à denúncia das estruturas racistas na sociedade, constroem personagens que fogem aos estereótipos comumente construídos sobre a população negra e fabulam existências complexas, que fogem da lógica dominação-dominado, mas que revelam a amplitude das relações subjetivas engendradas pelo racismo (Duarte 2011). Os autores e organizadores da Coletânea constantemente reforçam que sua escrita é uma literatura que espera ser lugar de modificação da realidade, pois carrega a "consistência do fruto-semente para a hora da transformação" (Cadernos Negros 1985:1).

Desde os primeiros volumes da Coletânea Cadernos Negros, no final da década de 1970, as mulheres negras e sua escrita possuem espaço consistente e suas presenças foram se tornando cada vez mais constantes com o decorrer dos anos. Uma dessas escritoras negras com maior visibilidade na contemporaneidade é Conceição Evaristo (1995), que refletindo sobre a prática da escrita das mulheres negras, cunhou o termo "escrevivências" para dar nome à literatura que possui como tema as experiências das mulheres negras na sociedade brasileira: "Quero rasurar essa imagem da "mãe preta" contando história. A nossa "escrevivência" conta as nossas histórias a partir das nossas perspectivas, é uma escrita que se dá colada à nossa vivência, seja particular ou coletiva, justamente para acordar os da Casa Grande" (Evaristo 2017). Essa escrita se constitui politicamente carregada de subjetividade, faz uso da memoria 
para expurgar a dor (Evaristo 2017), aciona novos referenciais e constrói narrativas de contraconduta"; é, assim, uma escrita com potência de vida.

Este trabalho está especialmente interessado em promover uma espécie de costura entre as "escrevivências" das autoras negras Esmeralda Ribeiro e Miriam Alves, ambas publicadas em 1985, no volume 8 dos Cadernos Negros, em formato de contos. Esmeralda Ribeiro - jornalista, poeta, ensaísta e contista; integrante do ainda vivo grupo Quilombhoje ${ }^{\text {III }}$ - e Miriam Alves - assistente social, professora, autora da maioria dos contos com personagens lésbicas afrobrasileiras dos Cadernos Negros - são autoras presentes em quase todas as publicações da coletânea. A escolha dos contos dessas duas escritoras justificase por parecerem dialogar no que tange as questões que apresentam. Suas obras trazem como temática as perspectivas de personagens negras e suas experiências atravessadas pelas dinâmicas das relações de poder decorrentes do racismo, do patriarcado e do capitalismo (estruturas coexistentes e interligadas, como vem defendendo as feministas interseccionais e decoloniais). Além disso, as autoras imaginaram e materializaram como personagens centrais de suas obras mulheres negras que desafiam - a partir de suas existências e atos - os papéis sociais e os estereótipos historicamente a elas destinados. Obras como essas abrem caminhos para perceber como a literatura feita por mulheres negras trata velhos temas de uma nova forma na constituição de narrativas repletas de experiências que são ao mesmo tempo individuais e coletivas, já que tratam tanto do lugar íntimo da constituição de quem são essas personagens como também acionam questões importantes para as lutas coletivas antirracistas e feministas. À

"Contracondutas são aqui entendidas, sob a luz de Michael Foucault, como novas chances de formulação da subjetividade, como a potência da construção inventiva de formas inéditas de existir e se colocar no mundo, novas maneiras de se relacionar consigo, com a vida e com os outros.

III Durante as reuniões para edição e publicação dos Cadernos Negros, as escritoras e escritores fundaram o Grupo Quilombhoje (1980), com a finalidade de discutir, aprofundar e disseminar a experiência afro-brasileira na literatura. Tanto Esmeralda Ribeiro como Miriam Alves são integrantes ativas do grupo Quilombhoje e autoras presentes em quase todas as publicações dos Cadernos Negros. Fizeram parte, portanto, de uma juventude negra que tinha por objetivo explícito combater o racismo através da literatura.

Revista Zona Franca- Centro de estudios interdisciplinario sobre las mujeres (CEIM)- Maestría poder y sociedad desde la problemática de género (MG), Rosario, Argentina. ISSN, 2545-6504 http://zonafranca.unr.edu.ar/index.php/ZonaFranca| Numero 27 (2019). Página 64 
essas experiências as escritoras negras desta geração atribuíram novas formas de interpretação e significação, e não o fizeram individualmente.

Dessa forma, me interessa neste artigo buscar a construção dos discursos sobre as mulheres negras - imagens, narrativas, referências etc. - presentes na literatura de Miriam Alves e Esmeralda Ribeiro, seguindo as pistas que nos levam a entender suas obras como discursividades que contribuem para a manifestação de uma perspectiva feminista, antirracista e democrática. Este trabalho possui como hipótese que pretende perseguir, portanto, a perspectiva de que a escrita dessas autoras é por si só movimento de contraconduta, ou seja, representam "possibilidades de construir inventivamente novas formas de se colocar no mundo, novas oportunidades de constituição da subjetividade, novas ideias para relacionar-se consigo e com os outros" (Pelegrini 2017: 98). Para isso, dois argumentos centrais serão aqui brevemente expostos: o primeiro consiste em admitir que o exercício de construção de narrativas sobre mulheres negras feito por escritoras negras constitui um exercício de cuidado de si, entendido aqui a partir das perspectivas de Michel Foucault. Depois, assumir a complexidade das questões de gênero e raça que permeiam as obras destas autoras - os contos "Ogum" de Esmeralda Ribeiro e "Um só Gole" de Miriam Alves, publicados em 1985 pelos Cadernos Negros - e, dessa forma, avançam e florescem no que são as buscas pelo encontro de subjetividades outras possíveis para as próprias mulheres negras. Por fim, este trabalho espera contribuir para a ampliação e visibilização da obra dessas escritoras, inserindo sua produção no que Michael Foucault chama de "formas de compreensão que o sujeito cria sobre si próprio" (Foucault 2004: 235).

\section{A escrita como espaço de reelaboração: o cuidado de si e as práticas de contraconduta}

Revista Zona Franca- Centro de estudios interdisciplinario sobre las mujeres (CEIM)- Maestría poder y sociedad desde la problemática de género (MG), Rosario, Argentina. ISSN, 2545-6504 http://zonafranca.unr.edu.ar/index.php/ZonaFranca| Numero 27 (2019). 
Em "Criação Crioula, nu elefante branco" (1987) - reunião de textos publicados em decorrência do I Encontro de Poetas e Ficcionistas Negros Brasileiros ocorrido em São Paulo em 1985 - Esmeralda Ribeiro apresenta seu "A escritora negra e o seu ato de escrever participando". Em apenas sete páginas a autora cita quinze outras escritoras negras atuantes e produzindo em plena década de 1980, em uma análise sobre suas trajetórias literárias e práticas de constituição de si:

“(...) devemos concordar com a escritora Sônia Fátima da Conceição, quando ela diz: ..."Para mim o importante está na nossa coragem de apesar de... estarmos aí, e de nossa ousadia de fazermos um trabalho que até então nos foi vetado por questões de parca intelectualidade". Esta parca intelectualidade provavelmente é decorrente da nossa limitação social, da falta de tradição escrita, da pressão política e econômica que sempre vivemos. A saída desta parca intelectualidade é a aquisição de conhecimento, através de uma profunda reflexão sobre o nosso trabalho, conjuntamente com outras escritoras." (RIBEIRO, 1987, p.85)

O convite de Esmeralda para uma autorreflexão conjunta sobre a produção da escrita da mulher negra é subversivo diante de uma teoria literária e historiografia que tradicionalmente propuseram-se a analisar majoritariamente os autores homens e brancos e as autoras brancas. Em outro texto, "A narrativa feminina publicada nos Cadernos Negros sai do quarto de despejo" (2002), Esmeralda Ribeiro aponta mais uma vez para o caráter coletivo dessa escrita ao ressaltar a importância de escritoras negras anteriores a ela para a constituição de toda escrita feminina negra contemporânea, dessa vez fazendo referência à Carolina Maria de Jesus. Esmeralda afirma que o processo de visibilização da produção literária feminina negra é o movimento de saída do "quarto de despejo", título do livro publicado por Carolina em 1960. Se o "quarto de despejo" é o "pior lugar que sobrou para nós negros e negras na sociedade", se "é como se disséssemos que estamos desalojadas do nosso próprio eu” (Ribeiro 2002: p.230), sair do quarto de despejo significa caminhar para um reencontro. Pego

Revista Zona Franca- Centro de estudios interdisciplinario sobre las mujeres (CEIM)- Maestría poder y sociedad desde la problemática de género (MG), Rosario, Argentina. ISSN, 2545-6504 http://zonafranca.unr.edu.ar/index.php/ZonaFranca| Numero 27 (2019). 
gentilmente emprestada a bonita análise que Mariléia de Almeida faz da obra de bell hooks, quando afirma que falar de si é um exercício de autorrecuperação, prática ética de cuidado de si que nunca está afastada do cuidado dos outros (Almeida 2019: 14). O cuidado de si, segundo Foucault, é um conjunto de ações de trabalho sobre si mesmo, culminando em uma ética da existência que constitui a possibilidade de diferenciados estilos de vida e, por isso, promove o surgimento de formas de resistência a mecanismos de poder e dominação como os engendrados pelos racismo e pelo patriarcado (Foucault 2010: 368). Em um mundo onde as opressões de raça e gênero fazem restar pouco tempo livre às mulheres negras, ser criativa e reelaborar sua própria existência a partir da literatura torna-se um ato de coragem e a ficção, abrigo: "sua criatividade é uma esfera de liberdade, uma esfera que a ajuda a lidar com a vida cotidiana e a transcendê-la" (Collins 2016:112). Como afirma outra escritora negra que publica nessa edição dos Cadernos Negros, Anita Realce, a escrita das mulheres negras contribui para um debate que rompe com o sufoco do silêncio:

"Seguindo os mesmos objetivos do Cadernos Negros 7 - no qual foram transcritos depoimentos dos escritores entrevistados - apresentamos este livro (antes dos contos) textos diversos, escritos pelos mesmos autores, versando sobre aspectos da literatura. Nosso intuito é o de fornecer ao leitor concepções dos autores dos contos acerca do próprio trabalho que fazem e seu envolvimento social. No caminho do debate, estamos rompendo o sufoco do silêncio imposto e que sempre tentou barrar nosso caminho." (Quilombhoje 1985: 5)

Nesse movimento, a autora destaca a importância dessa escrita para abordar "não só a literatura, como também o racismo contra a mulher negra em geral", e assim, despir as questões conflitivas resultantes de tanto racismo e preconceito (Realce 1985:7). Enquanto isso, Esmeralda Ribeiro dirige seu trabalho a "todas as pessoas que: - têm gingado no andar, estão nos guetos da vida e fazem do espelho sua própria realidade: de beiços, ventas, rugas mentais cravadas em episódios seculares" e que, por isso, acionam o enigma da resistência como luta

Revista Zona Franca- Centro de estudios interdisciplinario sobre las mujeres (CEIM)- Maestría poder y sociedad desde la problemática de género (MG), Rosario, Argentina. ISSN, 2545-6504 http://zonafranca.unr.edu.ar/index.php/ZonaFranca| Numero 27 (2019). 
concomitantemente individual e coletiva (Ribeiro 1985:9). Já Miriam Alves afirma que se os brancos negam os negros, ou os retratam com "um sorriso imbecil, eternamente pintado no rosto, igual a um bobo da corte" ou como um "ser ameaçador" (Alves 1985:13), a literatura feita pela própria população negra rompe com estas imagens ao se propor a falar de um lugar próprio, de uma interioridade própria: "A nossa fala desvela, delata, invade quem ouvi-la ou lê-la. Ela é a própria personificação do negro sendo, re-sendo, mudando, re-mudando, sentindo e resentindo" (Alves 1985:13). As escritoras, ao refletirem sobre si, sua escrita e o processo de visibilização crescente da literatura feminina negra, encontram em outras escritoras negras e escritores negros o lugar da coletividade e da reflexão que tensiona a luta política.

A ampliação dos espaços para uma literatura feita por mulheres é, como afirma Vânia Maria Ferreira Vasconcelos, "uma conquista recente e que vem sendo construída na contemporaneidade" (Vasconcelos 2014:10). Os textos de autoria feminina, apesar de constantes desde o Século XIX - principalmente nas publicações em periódicos, alguns destes criados e dirigidos pelas próprias mulheres - permaneceram durante muito tempo excluídos da historiografia literária, ganhando visibilidade apenas recentemente. Para Zahidé Muzart, esse processo de invisibilização das mulheres na literatura é um esquecimento político, não só porque as mulheres são esquecidas, mas porque as prioritariamente esquecidas são as "mais atuantes, as feministas, em uma palavra" (Muzart 2003:227). E se para as mulheres brancas escritoras as possibilidades de escrita e reconhecimento foram historicamente bem mais escassas do que para os homens, o cenário é bem mais violento e cheio de entraves para as mulheres negras. Segundo Regina Dalcastagnè (2005), em uma análise de 549 livros e 304 autores publicados entre 1990 e 2004, 94\% dos autores e 79\% dos personagens da literatura brasileira são brancos. Além disso, entre os autores, $72,7 \%$ são homens. O recente e ainda insuficiente aumento da visibilidade da produção literária das mulheres negras serve, como afirma bell hooks, para sublinhar tanto

Revista Zona Franca- Centro de estudios interdisciplinario sobre las mujeres (CEIM)- Maestría poder y sociedad desde la problemática de género (MG), Rosario, Argentina. ISSN, 2545-6504 http://zonafranca.unr.edu.ar/index.php/ZonaFranca| Numero 27 (2019). 
sua presença como sua ainda constante ausência (hooks 2019). A autora avança ainda ao sublinhar que os motivos desta ausência vão dos mais óbvios (o racismo, o machismo, a opressão de classe), até os menos óbvios (as lutas internas que travam as mulheres negras para ganhar a confiança necessária para escrever). Essa escrita torna-se, portanto, um "ato de coragem - um ato de risco e ousadia" (hooks 2019:31). Em um cenário literário que se constitui historicamente a partir de referenciais brancos, eurocêntricos e masculinos, onde a escrita e a publicação determinam o poder de ser quem fala e quem é ouvido e esses foram, geralmente, os homens brancos heterossexuais, ser uma mulher negra escritora é um ato primeiro de esvaziamento, como convida Gloria Anzaldua em: "Eu digo, mulher mágica, se esvazie. Choque você mesma com novas formas de perceber o mundo, choque seus leitores da mesma maneira. Acabe com os ruídos dentro da cabeça deles" (Anzaldua 2000:233) e completa:

"Escrever é perigoso porque temos medo do que a escrita revela: os medos, as raivas, a força de uma mulher sob uma opressão tripla ou quádrupla. Porém neste ato reside nossa sobrevivência, porque uma mulher que escreve tem poder. E uma mulher com poder é temida" (Anzaldua 2000:234).

\section{Raça, gênero e práticas de contraconduta nas escritas das mulheres negras nos Cadernos.}

O mesmo orixá regente do presente ano de 2019, segundo religiões tradicionais de matriz africana, empresta o nome também ao conto de autoria de Esmeralda Ribeiro publicado no volume de 1985 (no fim do regime ditatorial militar no país) na Coletânea Cadernos Negros. "Ogum", o orixá da guerra e do ferro, aquele que ajuda os viajantes que se perderam no caminho (Prandi 2001:100), é também título do texto que narra a trajetória de uma jovem mulher negra em direção a um reencontro com sua negritude, seu caminho de reconciliação com sua identidade.

Revista Zona Franca- Centro de estudios interdisciplinario sobre las mujeres (CEIM)- Maestría poder y sociedad desde la problemática de género (MG), Rosario, Argentina. ISSN, 2545-6504 http://zonafranca.unr.edu.ar/index.php/ZonaFranca| Numero 27 (2019). 
O conto tem como personagem principal a jovem Mariana Cesário, nascida em 20 de novembro de 1964 - até então Dia de Zumbilv, no ano do golpe militar no Brasil - em uma rua chamada Resistência. Mariana é filha de um pai negro e uma mãe italiana, que desde antes da separação por causa de "brigas raciais" já guardava profundo rancor do pai de sua filha: "Ao final de cada briga ela dizia: Meus pais sempre me alertaram. Não se case com preto, porque eles só querem saber de futebol, cerveja e... estudar que é bom nada" (Esmeralda 1985:33). A consonância da mãe de Mariana com um estereótipo muito presente no imaginário social brasileiro, o do negro malandro e preguiçoso, é apenas um dos elementos que tornaram difícil para Mariana Cesário a aproximação e identificação com sua própria negritude. A casa que Mariana dividia com a sua mãe era completamente branca, da pintura aos móveis, e entendo-a aqui como a materialização de um cenário onde um conjunto de aspectos externos produzidos pela branquitude ${ }^{v}$ (Carone 2012) atuam na constituição da subjetividade da personagem. Mariana parece "encapsulada em um casulo de brancura" (Gilliam 2013), uma mulher negra, como é apresentada logo no começo do conto, que se esforça para adotar e se encaixar nos padrões brancos da sociedade brasileira: Mariana usa roupas de estilo ocidental, insiste em regimes estéticos para ficar "magrinha" e diminuir suas curvas, alisa seu cabelo no salão "PORQUE VOCÊ NÃO ALISA O CABELO?" e possui um cargo de responsabilidade em um prédio do governo chamado "AQUI NÃO HÁ RACISMO". Vale chamar a atenção para o uso irônico dos nomes do salão que Mariana frequenta e do prédio do governo em que trabalha, que, conjuntamente com o nome do lugar do trabalho de sua mãe ("MENTES E CORPOS SÃOS") e o de seu namorado branco ("DINHEIRO LÍCITO/NÃO EXPLÍCITO") revelam um tom de ironia, resultante do emprego de títulos que tem um sentido oposto ao que se quer dizer, constantemente acionado

IV No ano de publicação do conto, o 20 de novembro ainda não era considerado Dia da Consciência Negra. O Dia de Zumbi só se tornou Dia da Consciência Negra no Brasil em 2003, após fortes pressões do movimento negro.

$\checkmark$ Branquitude entendida aqui como as características da identidade racial do branco brasileiro, suas estratégias e mecanismos de preservação da situação discriminante.

Revista Zona Franca- Centro de estudios interdisciplinario sobre las mujeres (CEIM)- Maestría poder y sociedad desde la problemática de género (MG), Rosario, Argentina. ISSN, 2545-6504 http://zonafranca.unr.edu.ar/index.php/ZonaFrancal Numero 27 (2019). 
por Esmeralda Ribeiro. O uso da ironia como recurso narrativo é comum entre as autoras que possuem uma poética feminista ${ }^{\mathrm{V}}$, como afirma Lúcia Helena Vianna (2002). Poética feminista, neste caso, marcada por uma consciência de natureza política onde, através da nomeação das instituições, é revelada uma consciência sobre os mecanismos culturais de unificação, de estereotipação e exclusão. A poética feminista de Esmeralda Ribeiro é apoiada pelo pensamento feminista negro $^{\mathrm{VII}}$, ou seja, em ideias produzidas por mulheres negras que trazem à luz pontos de vista de e para mulheres negras, nos quais é impossível separar conteúdo e estrutura de suas produções das condições materiais e históricas nas quais vivem (Berger \& Luckmann 1996).

Além dos nomes sugestivos das instituições que a cercam e dos incentivos para embranquecer seu corpo e comportamentos, os personagens com quem Mariana Cesário se relaciona constantemente se posicionam de forma a negar a existência do racismo, apoiados no mito da democracia racial ${ }^{\mathrm{VIII}}$ :

\begin{abstract}
"tinha ido até o prédio "AQUI NÃO HÁ RACISMO" reclamar para a atual coordenadora geral que havia sofrido racismo quando fora pleitear uma vaga de assistente de comércio exterior numa firma americana. A coordenadora respondeu-Ihe: - "talvez" tenha sido impressão sua, tente em outros lugares até conseguir o emprego. E, ressaltou: - Eu estudo
\end{abstract}

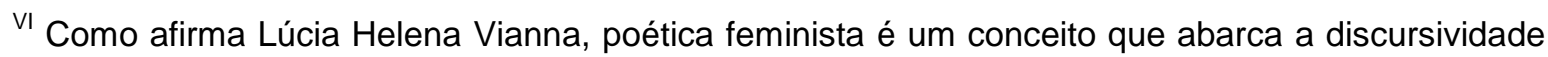
produzida pelas mulheres que, assumidamente ou não, contribui para o desenvolvimento e a manifestação da consciência feminista.

VII Entendendo "pensamento feminista negro" aqui na direção das reflexões de Patrícia Hill Collins; ou seja, um conjunto de produções teóricas e empíricas, acadêmicas ou não, produzido pelas mulheres negras no mundo e que expressam um ponto de vista coletivo e autodefinido das e sobre mulheres negras.

VIII Arthur Ramos, em seu primeiro livro sobre negros no Brasil, O negro brasileiro (1934), afirma que a religião africana era uma cultura atrasada por se basear em rituais mágicos primitivos. A partir daí inicia uma série de produções sobre a questão racial e concebe assim uma perspectiva sobre uma suposta democracia das raças no Brasil. Em Guerra e relações de raça (1943) o autor discute as relações raciais nos Estados Unidos e estabelece uma análise comparativa com a situação no Brasil, afirmando assim a existência de uma democracia racial no país. O chamado "mito da democracia racial no Brasil" se refere à ideia perpetradas por dezenas de intelectuais e estadistas brasileiros que, entre as décadas de 1930 e 1960, afirmaram que no Brasil não havia racismo devido ao seu caráter miscigenado. Esse "mito" foi, entretanto, constantemente denunciado pelo movimento negro no país.
}

Revista Zona Franca- Centro de estudios interdisciplinario sobre las mujeres (CEIM)- Maestría poder y sociedad desde la problemática de género (MG), Rosario, Argentina. ISSN, 2545-6504 http://zonafranca.unr.edu.ar/index.php/ZonaFrancal Numero 27 (2019). 
numa escola onde um dos meus professores é negro. - Por último, disse:

- você, Mariana, não deveria ser tão complexada" (Ribeiro 1985:39).

A amálgama do cenário descrito pela autora no conto revela a presença de discursos que atuam na construção da subjetividade da personagem, na formulação de si e sobre si, a partir de dinâmicas atravessadas por relações de poder engendradas na raça e no gênero (Foucault 1969): uma sociedade que nega o racismo evidente, induz Mariana Cesário vestir-se como uma mulher branca, alisar os cabelos para parecer-se com uma mulher branca no ocidente, constrói estereótipos racistas para a população negra, etc. O conto denuncia estruturas que compõem o que Sueli Carneiro chama de dispositivo de racialidade, lugar onde os discursos sobre a raça se articulam no sentido de construir relações de poder e formas de produção de subjetivação, valorando positiva ou negativamente certas estéticas e comportamentos, e o faz subjugando o que é negro e feminino, exaltando o que é branco e masculino (Carneiro 2005). Esse dispositivo de racialidade atua na elaboração de inúmeros tipos de violências, muitas delas presentes na narrativa do conto, como quando a mãe de Mariana a força, ainda na adolescência, a alisar os cabelos. A brutalidade desse processo forçado de "embranquecimento" é descrito quando Mariana:
“(...) foi em frente ao espelho conservar o alisamento do cabelo. Por um instante pegou uma mexa de cabelo e entregando-se aos pensamentos recordou quando, na puberdade, sua mãe agarrava seus cabelos com tanta força como se fosse arrancá-los, gritando-lhe: - dê um jeito nesse cabelo feio. Vê se pára com esse negócio de deixar o cabelo black. A impressão que se tem é que nem pente entra aí" (Ribeiro 1985:36).

A luta das mulheres negras em diversas partes do mundo passou - em momentos históricos distintos - pelo enfrentamento e desconstrução de padrões de beleza brancos e eurocêntricos, que de muitas formas obrigavam as mulheres a se submeterem a violências como essas descritas no conto.

Revista Zona Franca- Centro de estudios interdisciplinario sobre las mujeres (CEIM)- Maestría poder y sociedad desde la problemática de género (MG), Rosario, Argentina. ISSN, 2545-6504 http://zonafranca.unr.edu.ar/index.php/ZonaFranca| Numero 27 (2019). 
O conto de Miriam Alves, intitulado "Um só gole", permeia também pela elucidação desse dispositivo de racialidade ao contar a história da personagem Maria Pretinha, que diante de uma subjetividade construída pela dor, em um texto em primeira pessoa, narra as violências sofridas pelas opressões entrecruzadas de raça e gênero, enquanto caminha pela cidade confabulando e cogitando seu próprio suicídio: "Pensei em suicídio, várias vezes. Tenho medo. Muito medo. Não tenho medo de morrer, acho que é para isso que servem os suicídios. Sinto medo de viver" (Alves 1985: 67). No conto, a narradora-personagem atravessa reflexões que a fazem perceber os danos causados pelo racismo sofrido quando criança e que desencadearam suas angústias e vontade de não-viver. Segundo a personagem, foi após um episódio na escola que começou seu processo de "ausentar-se de si" (Alves 1985:68):

"Que sabe, a primeira vez que me arrastei foi aos pés de Ergos. Ergos, professor da escola municipal do Mandaqui. Ele tinha como prática organizar pecinhas de teatro para as crianças representarem nas datas festivas. Nas datas da abolição da escravatura eu fui à escrava que suplicava ao senhor para não Ihe bater a chicotes. Saí-me bem no papel. Talvez tivesse sido um treinamento para as outras tantas súplicas futuras. Pela ocasião do natal, Ergos faria representar o nascimento de Jesus. $\mathrm{Na}$ Escolha das personagens eu escolhi para ser Maria. Foi um riso só. (...) Fiquei olhando todos. Magoada sem entender. Ergos tentou convencerme a fazer a Camponesa "- Não, dizia eu". Afinal tinha me saído bem no papel anterior. Os risos aumentavam de intensidade. Diante de minha obstinação, Ergos disse: - "Maria não pode ser da sua cor", Chorei, lágrimas sorriam entrecortadas por soluços. Isto fazia a hilaridade da criançada que improvisava um coro: - "Maria não é preta, é Nossa Senhora. Maria não é preta, é mãe de Jesus". Corri sala afora. Corri dos colegas, da aula, da escola" (Alves 1985:68).

É importante pontuar que, segundo a Política Nacional de Saúde Integral da População Negra, o racismo, as desigualdades étnico-raciais e o racismo

Revista Zona Franca- Centro de estudios interdisciplinario sobre las mujeres (CEIM)- Maestría poder y sociedad desde la problemática de género (MG), Rosario, Argentina. ISSN, 2545-6504 http://zonafranca.unr.edu.ar/index.php/ZonaFrancal Numero 27 (2019). 
institucional são determinantes sociais das condições de saúde. Dessa forma, um dos grupos vulneráveis mais afetados pelo suicídio são pessoas negras e jovens.

Assim como Mariana Cesário, personagem do conto de Esmeralda Ribeiro, a Maria Pretinha de Miriam Alves passou pelo processo de envergonhar-se de quem era e de seus cabelos crespos, o que a levou ao doloroso processo de alisamento descrito em:

"Envergonhei-me de ser o que eu era: "Maria Pretinha". Envergonhei-me dos cabelos das pessoas pretas que riam e pulavam numa inconsciente alegria. Insanamente, me armei de pente-de-ferro-quente e a todo vapor tratei de amansar a rebeldia de meus cabelos. Neste momento ouvia aquelas vozes: "Há, há, há, ela quer ser Maria, mãe de nosso Senhor". Tentando apagar o vozerio, alisava os cabelos. Alisava-os. Esticava-os até não mais poder. Eu sabia, junto com os cabelos esticava a revolta. Domava minha consciência. Domava minha tolerância" (Alves 1985:68).

O cabelo é entendido aqui como um signo ideológico, sob a ótica do conceito desenvolvido por Bakhtin, onde o signo é entendido como sentidos sobre algo que são desenvolvidos dentro dos contextos sociais que o abrigam. Além disso, como afirma o pensamento feminista negro de Nilma Lino Gomes, "o cabelo é um dos elementos mais visíveis e destacados do corpo. Em todo e qualquer grupo étnico ele é tratado e manipulado, todavia a sua simbologia difere de cultura para cultura. Esse caráter universal e particular do cabelo atesta a sua importância como símbolo identitário (Gomes 2003: 174). As opressões intercruzadas de gênero e raça exercem-se, portanto, na intenção de fazer internalizar um ideal eurocêntrico, onde sobra às mulheres negras a formulação de um projeto identitário incompatível com as características de seu corpo: o alisamento de seus cabelos. A transformação física do cabelo da condição de cacheados, crespos ou enrolados - características naturais à população negra no Brasil - para o cabelo liso - comum às mulheres brancas - revela um condicionamento estético atrelado tanto à condição de feminilidade quanto de racialidade.

Revista Zona Franca- Centro de estudios interdisciplinario sobre las mujeres (CEIM)- Maestría poder y sociedad desde la problemática de género (MG), Rosario, Argentina. ISSN, 2545-6504 http://zonafranca.unr.edu.ar/index.php/ZonaFranca| Numero 27 (2019). 
É nessa tensão entre o ideal branco e as diversas características dos corpos negros das mulheres que Esmeralda Ribeiro constrói em "Ogum" a relação entre a personagem Mariana Cesário e seu namorado branco, um rapaz com um cargo no partido "DINHEIRO LíCITO/NÃO EXPLíCITO", de pele cor de papel sulfite e cabelos castanhos claros, que insistia em passar a mão pela pele do rosto negro com tonalidade vermelho artificial de Mariana e dizer-Ihe: "você é uma morena tão bonita". Esmeralda descreve a única vez em que se relacionaram sexualmente como um momento em que Mariana se sentiu um objeto em cima cama, um momento sem reciprocidade amorosa, onde a personagem sentia nos gestos do amante sua falta de respeito. Além disso, sem avisar, o então namorado viaja para casar-se com uma mulher alemã, presumivelmente branca. O que este homem parece apreciar em Mariana é justamente a armadilha do estereótipo da mulata e sua suposta sexualidade, além de encarar sua existência como mero objeto disponível para seu prazer. A objetificação da personagem revela-se como parte constituinte do processo de dominação a qual as mulheres negras são submetidas, como afirmam Brittan e Maynard (1964), todas as maneiras de oprimir envolvem a desvalorização da subjetividade do oprimido, a sua desumanização.

A constituição do estereótipo que marca a relação entre o casal vive no lugar da formulação histórica sobre os corpos das mulheres colonizadas e suas descendentes no Brasil. Na missão civilizatória colonial, o cristianismo impôs uma formulação sobre o pecado e a dicotomia entre mal e bem a fim de marcar a sexualidade feminina sob um viés negativo, maligno, referenciando as mulheres colonizadas e/ou escravizadas como "possuídas por satanás" por conta de seus comportamentos "libidinosos". O gênero e os discursos sobre a sexualidade feminina das mulheres não-brancas tornavam-se assim uma das formas de opressão colonial (Lugones 2014:939), e se estenderam para as representações posteriores que deram origem a certos imaginários nacionais.

Os textos literários, desde o século XVII, exploram, elaboram e moldam múltiplas imagens e práticas discursivas de gênero e raça em torno dos corpos

Revista Zona Franca- Centro de estudios interdisciplinario sobre las mujeres (CEIM)- Maestría poder y sociedad desde la problemática de género (MG), Rosario, Argentina. ISSN, 2545-6504 http://zonafranca.unr.edu.ar/index.php/ZonaFranca| Numero 27 (2019). Página 75 
femininos negros e mestiços e embora tais imagens, quando romantizadas, possam se sedimentar na cultura como aspectos inocentes e aparentemente despretensiosos, fazem parte de projetos e escolhas políticas, culturais e da produção do conhecimento no país. Romances, contos e poemas dedicaram-se a enquadrar e classificar o corpo feminino negro em um estereótipo ${ }^{\mathrm{IX}}$ (Bhabha 1998) ligado à malícia, sexualidade e imoralidade. Um corpo pronto para o consumo masculino, corpo-produto e corpo-objeto. A consequência prática dessa representação é denunciada no próprio ato da relação sexual entre Mariana e seu namorado, onde ele a fez sentir desrespeitada, tratada como um objeto.

É importante pontuar que as práticas discursivas de gênero e raça que produzem esse estereótipo - e atravessam a cena da relação sexual entre Mariana e seu namorado - foram constituídas historicamente no Brasil. Como afirma Margareth Rago, nas obras de autores consagrados como Paulo Prado (1928), Gilberto Freyre (1933), Caio Prado (1933) e Sérgio Buarque de Holanda (1936), o discurso da sexualidade ganha importância em uma leitura das origens históricas do país. Segundo a autora, nestas obras, as relações sexuais entre homens brancos e mulheres negras se tornam "a referência maior das características que explicam o povo brasileiro, sua índole e sua vocação" (Rago 1998:185). Em grande parte, essa historiografia afirma que a relação entre homens brancos e mulheres negras foi fator determinante para a construção de uma sociedade democrática racialmente, ignorando assim as instituições de violência e subordinação aos quais essas mulheres eram submetidas, valorando positivamente essas relações e seu resultado. Esse tipo de interpretação deu margem para que a violência sofrida pelas mulheres negras escravizadas fosse entendida como simples processo de "miscigenação", atribuindo a essas mulheres inclusive certo grau de responsabilidade, uma vez que elas teriam seduzido e encorajado os homens brancos. Neste contexto consolidava-se em importantes

\footnotetext{
${ }^{\mathrm{IX}}$ Estereótipo compreendido aqui como uma "forma presa, fixa, de representação, que, ao negar o jogo da diferença (que a negação através do outro permite), constitui um problema para a representação do sujeito em significações de relações psíquicas e sociais".
}

Revista Zona Franca- Centro de estudios interdisciplinario sobre las mujeres (CEIM)- Maestría poder y sociedad desde la problemática de género (MG), Rosario, Argentina. ISSN, 2545-6504 http://zonafranca.unr.edu.ar/index.php/ZonaFranca| Numero 27 (2019). Página 76 
textos a imagem da mulher negra sexualizada e objetificada. Além disso, utilizavase a mestiçagem como estratégia para minimizar o caráter opressor das relações raciais e perpetuar uma visão negativa dos corpos, personalidades e práticas das mulheres afrodescendentes; construindo um tipo de comportamento generalizante que tem sua origem na relação histórica da construção de seu papel social em uma sociedade escravista. Apesar dos sempre recorrentes relatos e fontes que confirmam a existência de estupros e coerção sexual sofridos por essas mulheres desde os tempos da escravidão, as conotações negativas insistentemente recaiam sobre elas próprias, acusadas por sua sexualidade exacerbada ou sua falta de inteligência. Essas concepções sobreviveram até os tempos atuais, presentes na música, na televisão, cinema, literatura e nos imaginários sociais em geral ${ }^{X}$. Além disso, o namorado de Mariana Cesário a substitui por uma alemã, que pode se supor com certa confiança que seria uma mulher branca. Sua atitude revela a presente concepção masculina que enquadra as mulheres brancas como "aptas ao casamento", ao contrário das mulheres negras.

"Visões racistas e preconceituosas em relação às mulheres negras e mestiças advindas do período escravista permaneceram até os dias de hoje, ainda que com "novas roupagens", principalmente a ideia de que as mulheres negras e mestiças possuem uma sexualidade diferenciada, mais acentuada. Muitas pessoas veem à mulher negra ou mestiça como a ideal para o sexo, porém jamais para o casamento ou um relacionamento amoroso mais sério e duradouro. É amplamente divulgada a ideia de que toda mulher negra ou mestiça é fácil e louca por sexo" (Silva 2008:2).

Apesar de ser entendida assim por seu namorado, Mariana Cesário é uma personagem que foge por completo desse estereótipo e de muitos outros aos

x Em "Olhares Negros: Raça e Representação", bell hooks demonstra como os signos e representações presente em diversos tipos de plataformas e mídias são racializados e atravessados por questões de gênero. No caso do Brasil, uma vasta literatura tem se desdobrado sobre as representações estereotipadas e racistas das mulheres negras na literatura, como é o caso do trabalho "Preconceito de Cor e a Mulata da Literatura Brasileira" de Teófilo de Queiroz Júnior, na música, televisão, etc.

Revista Zona Franca- Centro de estudios interdisciplinario sobre las mujeres (CEIM)- Maestría poder y sociedad desde la problemática de género (MG), Rosario, Argentina. ISSN, 2545-6504 http://zonafranca.unr.edu.ar/index.php/ZonaFrancal Numero 27 (2019). 
quais as mulheres negras são enquadradas historicamente. Finalmente este artigo espera se dedicar às formas com que Esmeralda Ribeiro subverte os padrões de comportamento esperados, constrói novas formas de significação para personagem e questiona as representações depreciativas sobre o corpo feminino negro. Mariana de afasta do estereótipo que seu próprio namorado cria sobre ela ao rejeitar o papel de objeto sexual e demonstrar anseio por uma relação que the proporcione a devida emoção, respeito e compromisso. Se as práticas discursivas de gênero e raça frequentemente buscam dissociar corpo e emoção ao tratar das mulheres negras - enfatizando o caráter corpóreo, sexual e voraz das mulheres negras em detrimento do aspecto emocional das mulheres brancas - Esmeralda Ribeiro constrói uma personagem que apresenta uma conduta distinta, real, que foge a esses padrões imaginados pelas práticas de controle.

Além disso, Mariana é uma funcionária exemplar, que deixa claro que jamais corresponderia a uma cantada dentro de seu ambiente de trabalho. Seu desempenho é tão bom e sua dedicação e empenho tão proeminentes que ela se torna candidata a uma promoção para o cargo de coordenadora geral. Esmeralda rompe com a representação da mulher negra desprovida de inteligência e capacidade e sempre disponível para as relações sexuais. Incentiva, portanto, representações mais complexas, positivas, que ao destoar dos estereótipos já conhecidos se apresentam como práticas de contraconduta ao proporem novas possibilidades de formulação de subjetividades para as mulheres negras. $O$ texto de Esmeralda traz duas características elencadas por Patricia Hill Collins como frequentes na escrita feminista negra: a autodefinição e a autoavaliação. A primeira consiste no deslocamento e desestruturação do processo de validação do conhecimento político que produz externamente os estereótipos sobre a condição feminina afro-americana, enquanto a autoavaliação trata-se de substituir essa imagens externamente definidas e estereotipadas por imagens mais autênticas e complexas.

Revista Zona Franca- Centro de estudios interdisciplinario sobre las mujeres (CEIM)- Maestría poder y sociedad desde la problemática de género (MG), Rosario, Argentina. ISSN, 2545-6504 http://zonafranca.unr.edu.ar/index.php/ZonaFranca| Numero 27 (2019).

Página 78 
Apesar de seu trabalho exemplar e de se apresentar como a melhor candidata para o cargo de coordenadora geral, Mariana não ganha a promoção, o que a faz perceber o quão vítima do racismo institucional seu corpo e existência podem ser. O que Esmeralda faz é zombar da perspectiva de um país democrático racialmente ao trazer à tona a constante discriminação a qual cidadãos não-brancos são submetidos diariamente. A repartição "AQUI NÃO HÁ RACISMO" é racista. Ao mesmo tempo, o mito da democracia racial é poderoso no sentido de obscurecer o caminho para uma consciência sobre a negritude. Como crítica voraz desse mito, Esmeralda narra a trajetória de uma personagem constituída por suas inúmeras tentativas de sobreviver a um mundo patriarcal e racista a partir da negação (não necessariamente consciente) dos aspectos da sua negritude.

Durante o conto, Mariana passa por um processo que escolhemos chamar aqui de processo de reconciliação, como o descrito por bell hooks, que caminha na direção da movimentação para além da dor, de um reencontro consigo mesma que Ihe fora constantemente negado em sua trajetória (hooks, 2019, p.28). Mariana pôde acessar privilégios que outras mulheres negras não poderiam, como um diploma universitário e um bom emprego. Essas conquistas, entretanto, apresentam uma ambiguidade que tensiona as relações raciais e de gênero no país: elas só foram possíveis devido ao processo de embranquecimento a qual a personagem foi submetida e, ao mesmo tempo, custaram esse afastamento violento de sua própria identidade, do seu encontro consigo. O processo de reconciliação tem início no momento em que Mariana Cesário, ao completar 20 anos, recebe de presente um telefone que seu pai lhe havia deixado de herança, "o primeiro e último presente de seu pai africano". A surpresa de Mariana é gigante quando o telefone de cor preta é revelado, visto que havia deixado bem clara sua preferência para que fosse um objeto branco. $O$ aparelho destoa da casa completamente branca na qual Mariana vivia com sua mãe e das próprias vidas das personagens. Ele é o legado que seu pai negro lhe deixou e, em um primeiro

Revista Zona Franca- Centro de estudios interdisciplinario sobre las mujeres (CEIM)- Maestría poder y sociedad desde la problemática de género (MG), Rosario, Argentina. ISSN, 2545-6504 http://zonafranca.unr.edu.ar/index.php/ZonaFranca| Numero 27 (2019). 
momento, causa profundos transtornos, tratado como um erro infeliz. O plano elastério que seu pai fez junto a companhia telefônica impede Mariana de vendêlo, ela só poderia doá-lo: o telefone parece que irá fazer parte permanente de sua vida e a personagem dele toma posse. Como parte de sua poética feminista, Esmeralda Ribeiro faz uso do telefone como objeto simbólico de um processo complexo pelo qual a personagem atravessa, a representação física de sua própria negritude, que a princípio lhe desconcerta.

Mariana decide permanecer com o telefone preto e leva-o para dentro de seu quarto, lugar de intimidade e interiorização. As tentativas de utilizá-lo, entretanto, são inicialmente frustradas. Apesar da companhia telefônica insistir que o aparelho está em condições perfeitas, Mariana não consegue fazer ligações com ele. Durante as tentativas privadas em seu quarto, inúmeras memórias da personagem são acionadas: a dor que sentia ao sua mãe alisar seu cabelo, o relacionamento sem sucesso com um ex-namorado negro, o encontro com seu corpo negro em frente ao espelho, etc. A relação com o telefone toma tanto sua mente que à noite um sonho estranho lhe ocorre:

\begin{abstract}
"o telefone preto transformou-se em um homem negro. Com as mãos dadas eles subiram uma escada de infinitos degraus. Carinhosamente disseram afetuosas palavras de amor nunca antes permitidas pela sua educação. Entregaram-se às delícias do sexo. Eles não cansavam de fazer carícias. No encontro dos olhos, diziam juntos: - nós somos lindos, lindos - e respeitaram-se mutuamente" (Ribeiro 1985:37).
\end{abstract}

Em outro momento, sonhou que denunciava o racismo que sofria à uma colega de trabalho e na ocasião usava seus "cabelos black"Xl e "roupas que tinham muito a ver com sua negritude". Acredito que os sonhos são o lugar primeiro do encontro da subjetividade da personagem com uma percepção sobre si carregada de negritude. Os sonhos Ihe revelam a beleza de seu corpo negro, de

\footnotetext{
${ }^{\mathrm{XI}} \mathrm{O}$ ato de assumir seu "cabelo black" faz referência ao chamado Movimento Black Power surgido nos anos 1960 nos Estados Unidos e que se espalhou para várias partes do mundo -, marcado pelo uso dos cabelos crespos naturais pela população negra.
}

Revista Zona Franca- Centro de estudios interdisciplinario sobre las mujeres (CEIM)- Maestría poder y sociedad desde la problemática de género (MG), Rosario, Argentina. ISSN, 2545-6504 http://zonafranca.unr.edu.ar/index.php/ZonaFranca| Numero 27 (2019). 
seu cabelo natural, de uma relação onde corpo e emoção se complementam, memórias que the permitem se explorar e nomear como uma mulher que se enxerga "linda, linda".

Historicamente a literatura masculina branca no Brasil ${ }^{X \|}$ codificou um conjunto de afirmações que enquadraram o comportamento das mulheres negras como imoral e lascivo, como um corpo-objeto, tratadas como uma diferença sexual negativa pela ideologia patriarcal, seres que necessitavam de controle e disciplina. Afastando-se dessa perspectiva, a escrita de Esmeralda revela uma narrativa onde a personagem, através do sonho, torna-se donas de sua sexualidade em um ato onde o homem com que se relaciona dedica-se ao seu prazer e aciona dimensões do sexo e das emoções. Como afirma bell hooks (2006), as opressões de gênero e raça colaboraram para afetar as possibilidades das mulheres negras de amarem e se sentirem amadas. Dessa forma, as narrativas onde a sexualidade, o prazer e o amor das mulheres negras são trazidas à tona, com doses altas de autoestima e autoafirmação, contribuem para a constituição de subjetividades outras na cura dessas "feridas emocionais": "a vontade de amar tem representado um ato de resistência" (hooks 2006:189). As cenas nos textos de Esmeralda e Miriam, portanto, fabulam novas possibilidade de viver prazeres e desejos corporais, transformando as representações sobre os corpos das mulheres negras. Revelam corpos prontos para viver sensações que não aquelas engendradas pelas constantes violências da branquitude, do racismo e do patriarcado; parte do processo de reconciliação.

Esse processo de reconciliação, entretanto, pode se revelar tão potente como doloroso e cansativo, revelando sua ambiguidade e complexidade. Quando sua relação com o telefone negro e sua própria negritude parece exaurir Mariana Cesário, ela acaba optando por doar o telefone à sua escola de samba preferida, a

XII Como, por exemplo, alguns dos autores citados por Teófilo de Queiros Júnior em seu "Preconceito de Cor e a Mulata na literatura brasileira": Manuel Antônio de Almeida (1852), Bernardo Guimarães (1875), José de Alencar (1865), Aluízio Azevedo (1890), João Guimarães Rosa (1956), Jorge Amado (1958), etc.

Revista Zona Franca- Centro de estudios interdisciplinario sobre las mujeres (CEIM)- Maestría poder y sociedad desde la problemática de género (MG), Rosario, Argentina. ISSN, 2545-6504 http://zonafranca.unr.edu.ar/index.php/ZonaFranca| Numero 27 (2019). Página 81 
"Sociedade Recreativa - Cultura Popular". Uma das cenas mais marcantes do conto se revelou para mim quando, no dia do desfile, o telefone aparece pintado de branco. A pintura torna o aparelho um objeto "nem preto nem branco", a tentativa de branqueamento não garantiu que sua negritude fosse completamente apagada. Ao ver o telefone na passarela, Mariana escuta uma voz que lhe diz "eu vou criar asas. Preciso saber quem eu sou. As dúvidas deles serão sempre as nossas certezas. Vem, vem, vem Marianinha". Ao chegar perto dela o telefone cria gigantes asas negras e voa para o infinito. Ao tentar fazer o mesmo, Mariana acaba caindo e sendo atropelada pela escola de samba que não quer perder pontos. A falta de um "final feliz" no conto, de um encerramento que designasse o reencontro completo de Mariana com sua negritude ou algo semelhante, apresenta a complexidade do processo que Esmeralda narra. $O$ encerramento confuso e ambíguo é em si uma escolha que descoloniza a literatura, uma vez que a própria disposição linear e coerente dos fatos é tradicionalmente vinculada a uma literatura eurocentrada. O que a autora produz é uma história que se revela nas minúcias, nas metáforas e na conexão com a subjetividade dos leitores. Uma narrativa que faz uso da ironia, da memória, do fantástico e da invenção para ficcionalizar os impasses das relações de gênero e raça.

É interessante perceber que nenhuma das escritoras não constrói uma trajetória de descoberta linear coerente e consciente, mas um processo múltiplo em que, se a princípio uma consciência sobre a negritude e as opressões raciais e de gênero não parecem tão claras para suas personagens, a narrativa acaba por revelar sua presença. Como afirma Patrícia Hill Collins, a relação entre opressão e consciência é muito mais complexa do que está apontado pela teoria social existente e

\footnotetext{
"as experiências das mulheres negras sugerem que essas talvez se conformem abertamente aos papéis sociais impostos a elas, mas secretamente se opõem a estes, oposição moldada pela consciência de se estar no escalão mais baixo da estrutura social (...) Nesse sentido, a consciência pode ser vista como esfera potencial de liberdade, que pode
}

Revista Zona Franca- Centro de estudios interdisciplinario sobre las mujeres (CEIM)- Maestría poder y sociedad desde la problemática de género (MG), Rosario, Argentina. ISSN, 2545-6504 http://zonafranca.unr.edu.ar/index.php/ZonaFrancal Numero 27 (2019). 
existir simultaneamente com um comportamento não liberto e alegadamente conformado" (Collins 2016:103)

O que é revelado não é um fim, um objetivo em si, uma trajetória completa, mas as complexidades de um processo profundo e difícil, principalmente devido à extensão que as práticas discursivas de gênero e raça possuem na construção da subjetividade das mulheres negras. Propõe, dessa forma, uma busca pelo oceânico caminho de volta na direção de uma ancestralidade que legitime seu lugar no mundo:

"Em última análise, Ribeiro lembra ao leitor que, apenas olhando para o passado em busca de sabedoria e orientação, os afro-brasileiros, em particular as afro-brasileiras, encontram força para aceitar sua identidade negra e trabalhar em conjunto com aqueles que ajudarão a soltar todos os vínculos que suprimem a participação política afro-brasileira e a prosperidade socieconômica no presente e no futuro" (Gilliam 2013, tradução nossa).

Descolonizar o pensamento é uma das tarefas mais árduas empreendidas pelos feminismos na atualidade e a escrita é um lugar privilegiado para este exercício. O que espero ter conseguido produzir, nesta breve reflexão, é uma análise que vá de encontro com que o feminismo decolonial tem proposto nos últimos tempos: uma crítica que parte do princípio que as narrativas presentes nas plataformas culturais - seja a música, a arte, a literatura - fazem parte de um processo constante de disputas que tensionam as memórias, leem o passado e projetam lugares sociais a partir das relações entre gênero e raça. Dessa forma, a literatura de Esmeralda Ribeiro e Miriam Alves abre espaço para questões importantes da luta coletiva feminista e antirracista, fundamentais para os avanços democráticos que esperamos. O lugar da produção de discursos, como território em disputa, é tensionado por escritoras negras que há muito mais anos que costumamos nos lembrar, pautam outras formas de existência para as mulheres negras que vão além dos estereótipos historicamente a elas destinados. Não há, portanto, descolamento da prática política. O exercício de elaborar a si própria a

Revista Zona Franca- Centro de estudios interdisciplinario sobre las mujeres (CEIM)- Maestría poder y sociedad desde la problemática de género (MG), Rosario, Argentina. ISSN, 2545-6504 http://zonafranca.unr.edu.ar/index.php/ZonaFranca| Numero 27 (2019). 
partir de personagens, cenários, denúncias e narrativas é, além de prática de liberdade para as mulheres negras, chance para que nos aproximemos epistemologicamente de um pensamento literário, social, histórico e político complexo, feminista e antirracista.

\section{Referências}

ALVES, Miriam (1985). Miriam Alves (depoimento). In: QUILOMBHOJE. Cadernos Negros 8 - Contos. São Paulo: Edição dos Autores. . (1985). Um só gole. In: QUILOMBHOJE. Cadernos Negros 8 Contos. São Paulo: Edição dos Autores, 1985.

ANZALDÚA, Gloria (1987) Borderlands/La Frontera: The New Mestiza. Aunt Lute Books, San Francisco.

ANZALDÚA, Gloria (2000)." Falando em línguas: uma carta para as mulheres escritoras do terceiro mundo", in Revista Estudos Feminista, N 229.

BHABHA, Homi K (1998). O local da cultura. Ed. da UFMG, Belo Horizonte.

CARNEIRO, Aparecida Sueli (2005). A Construção do Outro como Não-Ser como fundamento do Ser. Feusp, São Paulo. (Tese de doutorado)

CARONE, I; BENTO, M. A. S. (2002). Psicologia social do racismo. Vozes, Petrópolis.

COLLINS, Patricia Hill (2016). "Aprendendo com a outsider within: a significação sociológica do pensamento feminista negro" in Revista Sociedade e Estado, Volume 31, N 1.

DALCASTAGNÈ, Regina (2002). Uma voz ao Sol: representação e legitimidade na narrativa brasileira Contemporânea in Estudos de Literatura Brasileira Contemporânea. Brasília: julho/agosto, № 20.

DUARTE, Eduardo de Assis (2007). Literatura afro-brasileira: um conceito em construção; Márcio Barbosa; Esmeralda Ribeiro. (Org.). In A mente afro-brasileira: crítica literária e cultural afro-brasileira contemporânea/The afro-brazilian mind: contemporary afrobrazilian literary and cultural criticism. Trenton - EUA: Africa World Press, Inc., v. 1, p. 103-112.

Revista Zona Franca- Centro de estudios interdisciplinario sobre las mujeres (CEIM)- Maestría poder y sociedad desde la problemática de género (MG), Rosario, Argentina. ISSN, 2545-6504 http://zonafranca.unr.edu.ar/index.php/ZonaFrancal Numero 27 (2019). 
EVARISTO, Conceição (2011). Literatura negra: uma poética de nossa afrobrasilidade. In: SILVA, Denise Almeida; EVARISTO, Conceição. (Org.). Literatura, história, etnicidade e educação: estudos nos contextos afro-brasileiro, africano e da diáspora africana. Frederico Westphalen: URI.

FOUCAULT, Michel (2008). Nascimento da Biopolítica: curso dado no Collège de France (1978-1979). São Paulo: Martins Fontes.

. (1997). A Ordem do Discurso. Trad. Laura Fraga de Almeida Sampaio. São Paulo: Edições Loyola.

. (1988). A história da sexualidade: a vontade de saber.

Trad. Maria Thereza da Costa Albuquerque e J. A. Guilhon Albuquerque. Rio de Janeiro: Grall.

GILLIAM, Doris Waddell (2013). I Have to Know Who I Am": An Africana Womanist Analysis of Afro-Brazilian Identity in the Literature of Miriam Alves, Esmeralda Ribeiro and Conceição Evaristo. A Dissertation submitted to the College of Arts and Sciences in partial fulfillment of the requirements for the degree of Doctor of Philosophy.

GOMES, Nilma Lino (2003). Educação, identidade negra e formação de professores/as: um olhar sobre o corpo negro e o cabelo crespo. Educação e Pesquisa, São Paulo, v.29, n.1, p. 167-182, jan./jun.

hooks, bell (2019). Erguer a voz: pensar como feminista, pensar como negra. Editora Elefante, São Paulo.

. (1995). "Vivendo de amor". In: WERNECK, Jurema et al. (Orgs.).

O livro da saúde das mulheres: nossos passos vêm de longe. $2^{\underline{a}}$ edição. Rio Janeiro: Pallas.

MS. Portaria no 992/2009 - Institui a Política Nacional de Saúde Integral da População Negra.

QUEIROZ JÚNIOR, Teófilo de (1982). Preconceito de Cor e a Mulata da Literatura Brasileira. São Paulo: Ática.

Revista Zona Franca- Centro de estudios interdisciplinario sobre las mujeres (CEIM)- Maestría poder y sociedad desde la problemática de género (MG), Rosario, Argentina. ISSN, 2545-6504 http://zonafranca.unr.edu.ar/index.php/ZonaFranca| Numero 27 (2019). 
RAGO, Margareth (1998). Epistemologia feminista, gênero e história. In: PEDRO, Joana; GROSSI, Miriam (orgs). Masculino, feminino, plural. Florianópolis: Ed. Mulheres, 1998.

REALCE, Anita (1987). Anita Realce (depoimento). In: QUILOMBHOJE. Cadernos Negros 8 - Contos. São Paulo: Edição dos Autores, p. 7. . (1985). Penumbra. In: QUILOMBHOJE. Cadernos Negros 8 Contos. São Paulo: Edição dos Autores.

RIBEIRO, Esmeralda (1987). A Escritora negra e o seu ato de escrever participando". In Silva, Luiz (Cuti), Alves, Miriam; e Xavier, Arnaldo (orgs.) Criação crioula, nu elefante branco. São Paulo: Secretaria de Estado e Cultura. . (2002). A narrativa feminina publicada nos Cadernos Negros sai do quarto de despejo". In: DUARTE, Constância Lima et al. (orgs.) Gênero e representação na literatura brasileira. Vol. II. Belo Horizonte: UFMG, p. 229-233.

(1985). Esmeralda Ribeiro (depoimento). In: QUILOMBHOJE. Cadernos Negros 8 - Contos. São Paulo: Edição dos Autores, p. 9-10 . (1985). Ogum. In: QUILOMBHOJE. Cadernos Negros 8 - Contos. São Paulo: Edição dos Autores.

SILVA, Tadeu Tomaz (2007). A produção social da identidade e da diferença. In: Identidade e diferença: a perspectiva dos Estudos Culturais. $7^{\text {a }}$ Ed. Rio de Janeiro: Vozes. 